\title{
Mini Review of Cognitive Load Studies
}

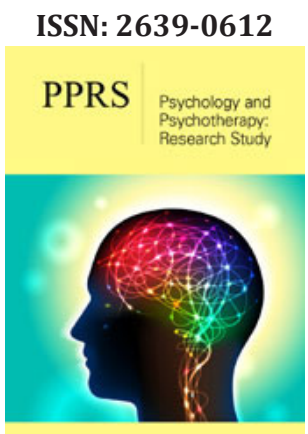

*Corresponding author: Hao Li, School of Medicine and Plateau Center of Brain Sciences, Tibet University, China The research was granted by the National Natural Science Foundation of Tibet(XZ2018ZR G-04)

Submission: 进 October 08, 2020

Published: 眥 October 28, 2020

Volume 4 - Issue 3

How to cite this article: Ting Wang, Hao Li. Mini Review of Cognitive Load Studies. Psychol Psychother Res Stud. 4(3). PPRS. 000587. 2020. DOI: 10.31031/PPRS.2020.04.000587

Copyright@ Hao Li, This article is distributed under the terms of the Creative Commons Attribution 4.0 International License, which permits unrestricted use and redistribution provided that the original author and source are credited.

\section{Ting Wang ${ }^{1}$ and Hao Li1 ${ }^{1,2 *}$}

${ }^{1}$ School of Psychological and Cognitive Sciences and Beijing Key Laboratory of Behavior and Mental Health, Peking University, China

${ }^{2}$ School of Medicine and Plateau Center of Brain Sciences, Tibet University, China

\section{Mini Review}

To date, related cognitive load studies and theories have been developed more than 70 years. As a result, listing and comparing relative theories will help form a better understanding. Cognition is "the mental action or process of acquiring knowledge and understanding through thought, experience, and the senses", which has the corresponding psychological mechanism [1]. It involves many features of psychological processes such as attention, working memory, problem solving and decision making. Early psychologists took considerable time to formalize their theories regarding cognitive resources. In psychology, cognition is usually used within an information processing view of an individual's psychological functions (Eysenck and Groome, 2015). In social cognition, the term is also used to explain attitudes, attribution, attention, and decision making. Attention is the first step of information processing in human brain, as a regulation mechanism of psychological activities, which has become a vital area of focus.

\section{Limited Cognitive Resource Theory}

There have been multiple theories regarding cognitive resources. One theory conceived by Kahneman explains that there is a single pool of attentional resources that can be freely divided among multiple tasks [2] and resources can be allocated to current tasks until the pool is exhausted [3]. This model seems too oversimplified, however, due to the different modalities (e.g., visual, auditory, verbal). Although viewing self-control as an energy resource has served as a convenient metaphor that explains a broad range of empirical findings, researchers suggested that self-control relied on glucose as a limited energy source. Studies have shown that the amount of information that individuals can process is severely limited (Marois and Ivanoff, 2005). That is, individuals can only selectively attend to a limited amount of information in the environment while other information is neglected [4].

When individuals perform a series of tasks, resource allocation could reflect a processing priority. That is, cognitive load in differing tasks is increased might lead to competing distribution of attentional resources. If they are engaged in a challenging task, their ability to handle distractor stimuli is relatively lower because fewer attentional resources available. In particular, studies have indicated that increasing attentional load affects processing (Macdonald and Lavie, 2011; Raveh and Lavie, 2015). Generally speaking, exploring attentional resources could show subsequent factors that influence the allocation (Matusz et al., 2015; Robinson \& Sloutsky, 2004, 2013). The rational-thinking economic theories has been taken greatly hit by the theory of limited cognitive resources as human are not always rational due to the limitations of cognitive resources. Individuals will make numerous bad decisions in the process of maximizing their own interests, and even bring losses.

\section{Bounded Rationality and Heuristic}

Bounded rationality refers when people make decisions, their rationality is restricted by the cognitive limitations of their minds, attentions, information processing ability, and the time available to make the decision [5]. Bounded rationality creates and impacts choice in a predictable way [6]. The other factor is heuristics that are strategies which use readily accessible information for problem solving. If it would be impossible or impractical to find a solution that are optimal, individuals use simple, efficient heuristics which have developed through either evolutionary proclivities or past learning to speed up decision-making process 
of finding a satisfactory solution. Mulligan (2013) describes probability as a heuristic, providing the decision maker with quality information about the degree of uncertainty at a relatively low cost. Easing the deciding's cognitive load, heuristics can be mental shortcuts (Parpart et al., 2018).

The well-known work of Kahneman and Tversky [7] is also applicable; they summarized three types of heuristics as anchoring and adjustment (the common human tendency to rely more heavily on the first piece of information offered when making decisions), availability heuristic (a mental shortcut that occurs when people make judgments about the probability of events by the ease with which examples come to mind)and representativeness heuristic (a mental shortcut used when making judgments about the probability of an event under uncertainty). Bounded rationality and heuristic are issues across many disciplines and widely used to study and model strategic decision-making scenarios, ranging from cognitive science and psychology to economics and law [8-12]. In general, bounded rationality enables individuals to habitually make social decisions with heuristics which is the most useful decisionmaking model in the brain-scarcity mode and the basic survival and adapting needs are guaranteed in most of the time, but it is not good enough to make far-reaching decisions, so it is impossible to help transform from poverty to wealth.

\section{Cognitive Load Theory}

Cognitive load refers to the effort used in the working memory and is differentiated into three types: intrinsic, extraneous, and germane (Paas et al., 2016). In this respect, prior research and theory (Mani et al, 2013) suggest an environment being impoverished contributes to cognitive load indicating people under poverty will experience higher cognitive load whatever they do. Studies have indicated that SES is an important predictor of neurocognitive performance, people with lower socioeconomic status bears the cognitive load that are not present in middle or upper-class people [13]. Based on a model of how human memory works, the cognitive load theory (CLT) indicates the load on working memory was placed by a set of cognition processes, such as comprehension and problem solving. When unneeded demands are imposed, cognitive load will be increased and if it gets too high, it blocks learning and transfer and decreases accuracy [14]. Learning is consequently impaired with the competing demands of processes being overloaded [14]. According to the basic premises of the CLT model, researchers conducted three experiments through the lens of working memory resource depletion (Chen et al., 2018). As cognitive effort may exhaust limited working memory resources, lessened performance may occur following substantial cognitive effort [14].

Cognitive Load Theory provided an integrative conceptual framework that not only identifies how cognitive resource allocation divided but also identify empirical role reducing cognitive load by memory model [15]. Currently, the cognitive theory mostly relies on the limited working memory model and is widely used on learning in the educational fields. Existing attempts to explore the new-developing theory is in urgent need and it would definitely suffer from conceptual and measurement challenges, but it may represent the direction of future research. The waring of scarcity is a guiding light in our population-explosion-increasing and limitedresource planet. The recent work reviewed here can be leveraged by policymakers to improve public benefit programs and help to alleviate the condition of scarcity in the poor.

\section{References}

1. Ardila A (2017) Historical development of human cognition: A culturalhistorical neuropsychological perspective. Springer, Singapore.

2. Kahneman D (1973) Attention and effort. Englewood Cliffs, PrenticeHall, New Jersey, USA.

3. Leahy W, Sweller J (2019) Cognitive load theory, resource depletion and the delayed testing effect. Educational Psychology Review 31: 457-478.

4. Wahn B, König P (2017) Is attentional resource allocation across sensory modalities task-dependent? Adv Cogn Psychol 13(1): 83-96.

5. Simon HA (1982) Models of bounded rationality. MIT Press, Cambridge, Mass, Massachusetts, United States.

6. Mahmoudi M, Pingle M (2018) Bounded rationality, ambiguity, and choice. Journal of Behavioral and Experimental Economics 75: 141-153.

7. Kahneman D, Slovic P, Tversky A (1982) Judgment under uncertainty: Heuristics and biases. Cambridge University Press, Cambridge, New York, USA

8. Gershman SJ, Horvitz EJ, Tenenbaum JB (2015) Computational rationality: A converging paradigm for intelligence in brains, minds and machines. Science 349: 273-278.

9. Hills TT, Todd PM, Lazer D, Redish AD, Couzin ID (2015) Exploration versus exploitation in space, mind and society. Trends Cogn Sci 19(1): 46-54.

10. Korobkin R (2015) Daniel Kahneman's influence on legal theory. Loyola University Law Journal 44(5): 1346-1349.

11. Luan S, Schooler LJ, Gigerenzer G (2014) From perception to preference on to inference: An approach-avoidance analysis of thresholds. Psychol Rev 121(3): 501-525.

12. Puranam P, Stieglitz N, Osman M, Pillutla M (2015) Modelling bounded rationality in organizations: Progress and prospects. Academy of Management Annals 9(1): 337-392.

13. Hackman DA, Farah MJ (2009) Socioeconomic status and the developing brain. Trends Cogn Sci 13(2): 65-73.

14. Sweller J, Van Merriënboer JJ, Paas F (2019) Cognitive architecture and instructional design: 20 years later. Educational Psychology Review 31: 261-292.

15. Puma S, Matton N, Paubel PV, Tricot A (2018) Cognitive load theory and time considerations: Using the time-based resource sharing model. Educational Psychology Review 30(3): 1199-1214.

For possible submissions Click below: 